\title{
Effect of zinc soaps of rubber seed oil (RSO) and/or epoxidised rubber seed oil (ERSO) on the thermal stability of PVC plastigels
}

\author{
Theresa Obuajulu Egbuchunam ${ }^{\text {a }}$, Devrim Balköse ${ }^{\text {b,* }}$, Felix Ebhodaghe Okieimen ${ }^{\text {a }}$ \\ ${ }^{a}$ University of Benin, Faculty of Physical Science, Department of Chemistry, Benin City, Nigeria \\ b Izmir Institute of Technology, Faculty of Engineering, Department of Chemical Engineering, Gülbahçeköyü, Urla, Izmir, Turkey
}

Received 7 February 2007; received in revised form 26 March 2007; accepted 1 May 2007

Available online 18 May 2007

\begin{abstract}
Zinc soaps of rubber seed oil (RSO) and epoxidised rubber seed oil (ERSO) were prepared and their use as PVC stabilizers investigated. Characterization of $\mathrm{Zn}$ soaps of RSO prepared by different techniques and ERSO gave information on the purity, structure and thermal behaviour of these materials. From the analysis, the production of these materials for use in thermal stabilization of PVC would be optimized as their use greatly enhanced the stability of PVC as obtained from the conductivity measurements using the 763 PVC Thermomat. The minimum amount of $\mathrm{HCl}$ release was obtained for the samples with $\mathrm{Zn}$ soaps and ERSO indicating a synergistic effect. $\mathrm{Zn}$ soaps having $\mathrm{Zn}(\mathrm{OH})_{2}$ stabilized $\mathrm{PVC}$ better than pure $\mathrm{Zn}$ soaps.
\end{abstract}

(c) 2007 Elsevier Ltd. All rights reserved.

Keywords: Rubber seed oil; Metal soaps; Epoxidised rubber seed oil; PVC thermal stabilization; Plastisols

\section{Introduction}

Poly(vinyl chloride) (PVC) is one of the most frequently used polymers and significant amount is processed in the form of plastisols. These are produced by mixing PVC powder with a plasticizer including other additives aimed at improving and controlling the properties of the final product. When plastisols are heated, diffusion of plasticizer into PVC particles, swelling of the particles and fusion of swollen particles to a solid mass occur simultaneously and a plastigel forms. Plastisols are mainly used for producing flexible articles such as artificial leather and shower curtains. Since thermal treatment is required for plastisol gelling, heat stabilizers should be added to plastisols to prevent discoloration of product during gelling and for retardation of release of dehydrochlorination product to the surroundings in case of fire.

\footnotetext{
* Corresponding author.

E-mail address: devrimbalkose@iyte.edu.tr (D. Balköse).
}

It is well known that PVC undergoes degradation with increasing temperature in a process called "zip dehydrochlorination" involving the elimination of hydrogen chloride and the formation of conjugated double bonds followed by a change in the polymer's colour which goes from yellow to orange, red, brown and finally black $[1,2]$.

The poor thermal stability of PVC requires the use of heat stabilizers in its processing and the role of different types of stabilizers is to bond the eliminated hydrogen chloride or to replace the labile chlorine atoms in PVC chains to prevent further dehydrochlorination. The mechanisms for the thermal stabilization of PVC and its compounds with additives such as metal carboxylates, organo-tin compounds, epoxy compounds, zeolitic materials and metal oxides have been discussed in recent reviews [1,3-8]. There are a number of studies regarding the use of zinc stearate and/or epoxidised oil as heat stabilizer for PVC $[1,9,10]$. The carboxylates derived from zinc have strong Lewis acidity and are able to scavenge $\mathrm{HCl}$ and react with the allylic chlorine atom resulting in the formation of $\mathrm{ZnCl}_{2}$ which promotes dehydrochlorination of PVC [7,11]. 
However, in the catalytic presence of $\mathrm{ZnCl}_{2}$, the epoxy compounds react with the chloride to produce a chemical species that is able to remove allylic chlorine atoms in PVC chains [11-13].

Rubber seed oil (RSO) is an unsaturated triglyceride abundantly available in Nigeria, India and Australia and is an excellent starting material for many products such as metal soaps and epoxy compounds for the processing of polymers $[3,10,14,15]$, alkyd resins and the production of bio-diesel $[16,17]$. The unsaturated double bonds present in RSO have been converted into the more reactive oxirane moiety by reaction with peracids or peroxides and epoxidised rubber seed oil (ERSO) has been shown to retard the dehydrochlorination of PVC using rate measurements obtained from a degradation tube $[3,10,14]$. However, these studies have been devoted to the study of the pure polymer although PVC is most often used in its plasticized form. ERSO is highly soluble in the most known plasticizer dioctyl phthalate (DOP) and it is a good candidate as a thermal stabilizer for PVC plastisols prepared from DOP. Due to the sustained availability of RSO in Nigeria, development of economically feasible products for use in industrial processes is highly desirable. In all these fields, understanding the structure, phase transitions and thermal properties is essential as it may lead to greatly improved products or processes. $\mathrm{Zn}$ metal soaps are known as efficient stabilizers for PVC [18] and that thermal stability can be reinforced by the addition of epoxidised compounds [19].

This study aims at characterizing Zn soaps of RSO prepared by two different techniques. The thermal dehydrochlorination behaviour of PVC plastisols with $3 \mathrm{wt} \% \mathrm{Zn}$ soap and/or $3 \mathrm{wt} \%$ ERSO would then be examined by the 763 PVC Thermomat and compared with that of unstabilized PVC plastisols to understand the effect of the additives derived from RSO on PVC plastisol thermal stability.

\section{Experimental}

\subsection{Materials}

PVC, a product of Petkim, Turkey (Petvinil P. 38/74) emulsion type resin was used as received. The average molecular weight of this resin obtained from gel permeation chromatography (GPC) was $M_{\mathrm{w}}=1.96 \times 10^{5}$ and the polydispersity ratio $M_{\mathrm{w}} / M_{\mathrm{n}}=3.74$. DOP $(98 \%$, Merck) with specific gravity $0.98 \mathrm{~g} \mathrm{~mol}^{-1}$ and molecular weight $390.5 \mathrm{~g} \mathrm{~mol}^{-1}$ was used as the plasticizer. RSO was obtained from Rubber Research Institute of Nigeria, Iyanomon, Benin City. The physicochemical properties and fatty acid composition of the oil have been reported previously [20]. Fatty acid composition was $2.2 \%$ myristic acid, $7.6 \%$ palmitic acid, $10.7 \%$ stearic acid, $20.61 \%$ oleic acid, $36.62 \%$ linoleic acid, and $22.50 \%$ linolenic acid. The epoxidation of the oil was carried out with $30 \% \mathrm{H}_{2} \mathrm{O}_{2}$ and formic acid [16]. The level of oxirane oxygen was $4.6 \%$. The stabilizers used were $\mathrm{Zn}$ soaps prepared by metathesis in alcohol solution [20] and the precipitation technique [21].

\subsection{Preparation of zinc soaps of $R S O$}

The soaps of RSO using the hydrated form of zinc sulphate, $\left(\mathrm{ZnSO}_{4} \cdot 7 \mathrm{H}_{2} \mathrm{O}\right)$, were prepared by precipitation and metathesis in alcohol solution. Both processes are double decomposition reactions involving the synthesis of the $\mathrm{Zn}$ soap from sodium soap. The difference in method lies in the use of alcohol in metathesis to accelerate the rate of conversion of the oil to the sodium soap. Sodium soap of RSO containing 5.1\% Na (prepared by mixing $0.01 \mathrm{~mol} \mathrm{RSO}$ and $0.1 \mathrm{~mol} \mathrm{NaOH}$ ) and which was a mixture of unconverted oil and soap was used in the experiments. In precipitation reaction, $5 \mathrm{~g}(0.016 \mathrm{~mol})$ of the sodium soap was dissolved in $200 \mathrm{ml}$ of deionised water at $70{ }^{\circ} \mathrm{C}$ in a water bath. The $\mathrm{pH}$ value was measured as 9.01 at $25^{\circ} \mathrm{C}$. After the complete dissolution of the sodium soap, $0.015 \mathrm{~mol}$ of $\mathrm{ZnSO}_{4} \cdot 7 \mathrm{H}_{2} \mathrm{O}$ was slowly added with continuous stirring. The precipitated metal soap was washed several times with deionised water, filtered, air-dried and dried in an oven under $400 \mathrm{mmHg}$ vacuum at $30^{\circ} \mathrm{C}$. A typical reaction equation is

$2 \mathrm{RCOO}_{(\mathrm{aq})}^{-}+2 \mathrm{Na}_{(\mathrm{aq})}^{+}+\mathrm{Zn}_{(\mathrm{aq})}^{2+} \rightarrow\left(\mathrm{RCOO}^{-}\right)_{2} \mathrm{Zn}_{(\mathrm{s})}+2 \mathrm{Na}_{(\mathrm{aq})}^{+}$

where $\mathrm{R}$ represents the alkyl group of the acid (myristic, palmitic, stearic, oleic, linoleic or linolenic acid) in rubber seed oil.

The metal soaps of RSO were prepared by metathesis involving two steps: hydrolysis and precipitation. $9.2 \mathrm{~g}$ $(0.01 \mathrm{~mol})$ of the oil was first dissolved in $50 \mathrm{~cm}^{3}(0.86 \mathrm{~mol})$ of boiling ethanol followed by treatment of the mixture with $20 \mathrm{~cm}^{3}(0.1 \mathrm{~mol})$ of $20 \%$ (w/v) sodium hydroxide solution. To this mixture, $100 \mathrm{~cm}^{3}$ of $30 \%$ (w/v) solution of the $\mathrm{Zn}$ metal salt $(0.11 \mathrm{~mol})$ was slowly added with continuous stirring. The precipitated soap was washed with $100 \mathrm{ml}$ deionised water several times until the conductivity of the filtrate reached $2 \mu \mathrm{S} \mathrm{cm}^{-1}$, followed by washing with petroleum ether. The synthesized soaps were dried in a vacuum oven at $60{ }^{\circ} \mathrm{C}$ to constant weight. The EDX analysis and IR spectra showed them to be free of excess metal salts.

\subsection{Preparation of $P V C$ films}

PVC and DOP were mixed with a mechanical mixer (IKA Labortechnik) at room temperature for $30 \mathrm{~min}$. The formulation consisted of 10 parts of PVC, 8 parts of DOP and $0.5 \mathrm{ml}$ viscobyk 5025 as wetting agent. The additives, $3 \mathrm{wt} \% \mathrm{Zn}$ soap of RSO in the presence and absence of $3 \mathrm{wt} \%$ ERSO were added and mixed to form a homogeneous mixture using a porcelain mortar. The films were prepared using a $90-\mu$ film applicator (Sheen $113 \mathrm{~N}$ ) and gelled for $15 \mathrm{~min}$ in an air-circulating oven (EV 018) at $140 \pm 3{ }^{\circ} \mathrm{C}$ to obtain the plastigels.

\subsection{Characterization of ERSO and Zn soaps of RSO}

No information about the purity, thermal stability or structural data of the metal soaps of RSO and ERSO has been reported. Different characterization tools have been used to identify the structure, thermal stability and transition behaviour of these additives. The morphology of the $\mathrm{Zn}$ soaps of 
RSO prepared by both methods was determined using a scanning electron microscope (Philips XL 30 S FEG) coupled with a secondary electron imaging (SEI) detector. Samples were coated with gold using the sputtering technique. A Philips XLFE6 EDX analyser was used to determine the metal content of the soap samples. Data were collected from 10 randomly chosen points and the average weight percent of the elements calculated.

The infrared spectra of ERSO and the soaps were obtained using a Digilab Excalibur Series FTS 3000MX spectrophotometer using the transmission technique. The range of the spectra was $400-4000 \mathrm{~cm}^{-1}$ and the $\mathrm{KBr}$ disc method was used to obtain pellets for analysis. Dynamic thermal degradation measurements on ERSO and the $\mathrm{Zn}$ soaps were performed using a Shimadzu TGA-51 instrument. The samples were heated from 25 to $600{ }^{\circ} \mathrm{C}$ at $10{ }^{\circ} \mathrm{C} \mathrm{min}^{-1}$ under nitrogen. To study the thermal processes responsible for the changes in the crystalline state of the samples, differential scanning calorimetry (DSC) measurements were carried out using a Shimadzu DSC-50 analyser. Samples were heated to $200{ }^{\circ} \mathrm{C}$ at $10{ }^{\circ} \mathrm{C} \mathrm{min}^{-1}$ under $40 \mathrm{~cm}^{3} \mathrm{~min}^{-1}$ nitrogen flow. Melting temperatures of the $\mathrm{Zn}$ soaps of RSO were also determined using transmission optical microscopy (Olympus, CH40) with a heated stage controlled by a temperature controller (Instec, STC 200C) and the melting was photographed by a digital camera (Nikon, Coolpix 995). A Philips X'Pert Pro diffractometer was used to investigate the purity and crystalline form of the elements present in the soap samples. The operating conditions were $45 \mathrm{kV}$ and $40 \mathrm{~mA}, \mathrm{Cu} \mathrm{K} \alpha$ radiation, $\lambda=1.54 \AA$. The measurements were performed in the range of $2 \theta$ values of $5-70^{\circ}$ with a scan speed of $0.06^{\circ} \mathrm{s}^{-1}$.

\subsection{PVC thermal stability}

\subsubsection{Static oven test}

Plastigel films were heated at $160{ }^{\circ} \mathrm{C}$ for $30 \mathrm{~min}$ in a temperature-controlled oven. Yellowness index values before and after heating were measured by using an Aventas Spectrocam.

\subsubsection{PVC Thermomat test}

Dehydrochlorination studies were carried out at 140 and $160{ }^{\circ} \mathrm{C}$ in a Metrohm $763 \mathrm{PVC}$ Thermomat. In a previous study [6], the measuring arrangement, experimental procedure and kinetic data obtained from conductivity measurements using the 763 PVC Thermomat have been discussed in detail. The rate of dehydrochlorination of PVC is determined by measuring the conductivity of the solution to which the evolved $\mathrm{HCl}$ gas is transferred. In a typical experiment, the films were cut into $0.5 \times 0.5 \mathrm{~cm}$ squares and $0.5 \mathrm{~g}$ placed in the reaction vessel and transferred into the Thermomat when the temperature reached the set value. Nitrogen gas was then passed through the reaction vessel and the evolved $\mathrm{HCl}$ absorbed by the measuring vessel filled with deionised water. The conductivity of the solution changed with time and the decomposition was monitored by measuring the conductivity of the aqueous $\mathrm{HCl}$ solution. The induction time shows the period at which a sharp change in slope of conductivity curve occurred, the period over which $\mathrm{HCl}$ is not evolved from the PVC. $\mathrm{HCl}$ either does not form or it is removed from the system by stabilizers. This point is found from the intersection points of tangents to the conductivity versus time curve before and after the slope first changes and the software of the instrument reports this point. Stability time is the time required for the conductivity to reach $50 \mu \mathrm{S} \mathrm{cm}^{-1}$. After this period, $\mathrm{PVC}$ is assumed to be thermally degraded.

\section{Results and discussion}

\subsection{Characterization of Zn soaps of $R S O$}

\subsubsection{EDX analysis}

EDX is a powerful tool for chemical analysis for elements having atomic number greater than four. The results for the EDX measurements of Zn soaps of RSO prepared by precipitation and metathesis in alcohol solution together with the theoretical values on a hydrogen free basis are shown in Table 1 . According to the EDX analysis, the common elements are C, $\mathrm{O}$ and $\mathrm{Zn}$. From the comparison of the experimental results obtained for the soaps prepared using two techniques, $\mathrm{Zn}-1$ had values similar to the theoretical value except for the $\mathrm{Zn}$ metal content which was lower and could be assigned to the low sodium content of the sodium soap $(5.51 \%)$ used as the starting material. The material balance on $\mathrm{C}, \mathrm{O}$ and $\mathrm{Zn}$ indicated that it contained $44 \%$ unconverted free oil. The $\mathrm{O}$ and $\mathrm{Zn}$ content of $\mathrm{Zn}-2$ was exceptionally higher (between 70$80 \%$ ) than the theoretical values. A possible explanation for this observation could be the formation of the insoluble $\mathrm{Zn}(\mathrm{OH})_{2}$ arising from the excess use of sodium hydroxide and the metal salt required for complete reaction during soap preparation. When a material balance was done from chemical analysis it was found that roughly $40 \%$ of the zinc is present in soap form and $60 \%$ in hydroxide form.

During saponification, hydrolysis and precipitation occur as shown in Eqs. (2) and (3).

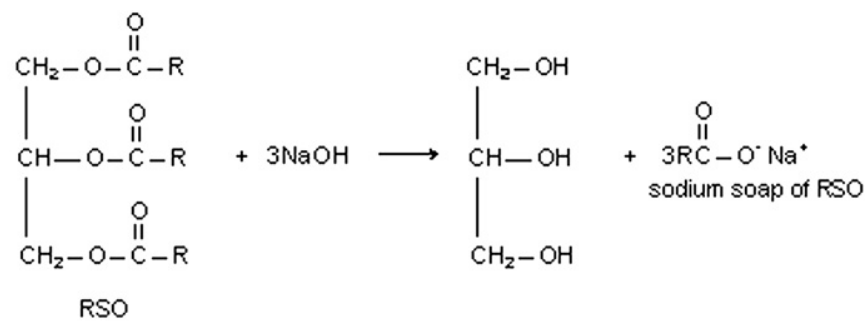

( $R$ = Myristic, palmitic, stearic, oleic, linoleic and linolenic acids).

Table 1

Elemental composition of Zn soaps of RSO excluding hydrogen element from EDX measurements

\begin{tabular}{llll}
\hline Elements & Theoretical & EDX & \\
\cline { 3 - 4 } & & Precipitation $(\mathrm{Zn}-1)$ & Metathesis $(\mathrm{Zn}-2)$ \\
\hline $\mathrm{C}$ & 76.99 & 81.33 & 59.83 \\
$\mathrm{O}$ & 11.41 & 11.70 & 19.35 \\
$\mathrm{Zn}$ & 11.59 & 6.74 & 20.82 \\
\hline
\end{tabular}




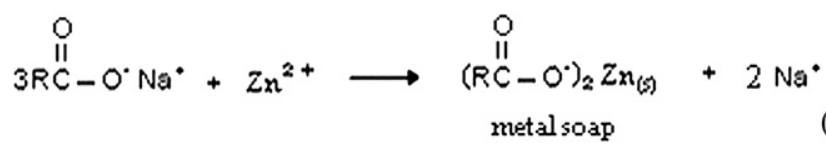

Unreacted $\mathrm{Zn}^{2+}$ reacts with the excess hydroxide ions to form the hydroxide as shown in the reaction

$\mathrm{Zn}_{(\mathrm{aq})}^{2+}+\mathrm{OH}_{(\mathrm{aq})}^{-} \rightarrow \mathrm{Zn}(\mathrm{OH})_{2(\mathrm{~s})}$

\subsubsection{Morphology of the soap samples}

The morphology of the $\mathrm{Zn}$ soap particles is shown in Fig. 1. The samples exhibit similar plate-like microstructures except that the particles of $\mathrm{Zn}-2$ were more orderly packed than the ones present in $\mathrm{Zn}-1$. This behaviour is consistent with the observed crystal structures observed for $\mathrm{ZnSt}_{2}$ produced by the precipitation and fusion processes [21].

\subsubsection{Crystal structure}

Fig. 2 shows the X-ray diffraction patterns of the sodium and zinc soaps of RSO. An overview of the X-ray diffraction pattern of $\mathrm{Na}$ soap yielded broad plateau-like peaks assigned to hydrogen-bonded carboxylate complex of soaps and
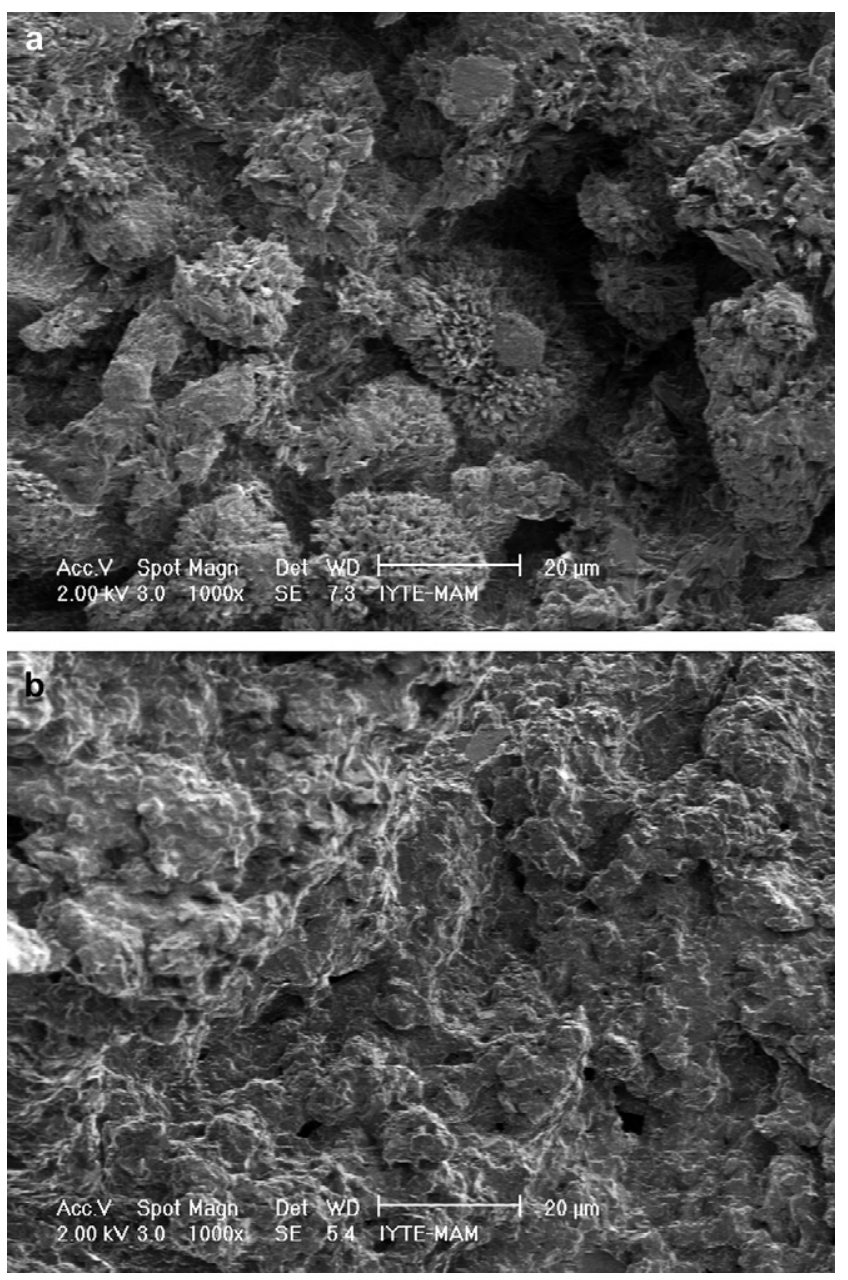

Fig. 1. SEM micrographs of Zn soaps of RSO produced by (a) precipitation, Zn-1 and (b) metathesis, Zn-2.

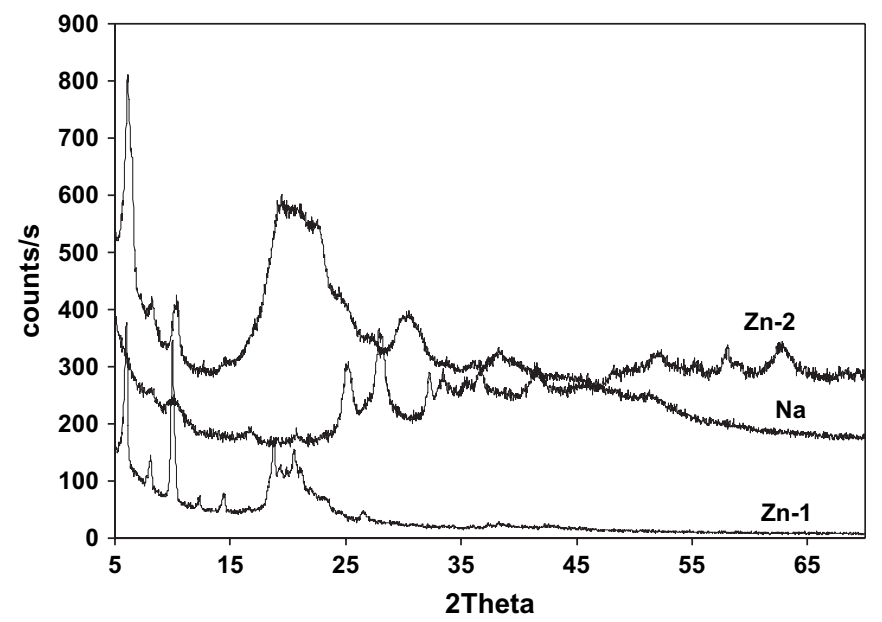

Fig. 2. X-ray diffraction patterns of $\mathrm{Na}$ and $\mathrm{Zn}$ soaps of RSO produced by (a) precipitation, Zn-1 and (b) metathesis, Zn-2.

observed at $2 \theta=5.20,7.40,10.40,19.70$ and 28.80 . The inter-layer distance of sodium soap was found to be $4.7 \mathrm{~nm}$ from the third, fourth and fifth order diffractions of inter-layer distance at 5.20, 7.40, and 10.40. XRD patterns obtained for the $\mathrm{Zn}$ soaps varied considerably in overall intensity even though the same oil was used. The diffraction peaks for $\mathrm{Zn}-1$ were sharper than those of $\mathrm{Zn}-2$ indicating a relatively well-formed crystalline-layered structure for $\mathrm{Zn}-1$. The pattern for $\mathrm{Zn}-1$ showed a series of sharp, fairly intense peaks between $2 \theta=5^{\circ}$ and $10^{\circ}$ and a second group between $18^{\circ}$ and $25^{\circ}$. The inter-layer distance of metal soaps depends on the length of the alkyl chain and the angle they make with the normal to metal ion plane. Since RSO contains alkyl groups with different chain lengths and different number of double bonds, a distribution of inter-layer distance is expected. From the third, fourth and fifth order diffractions of inter-layer distance, $\mathrm{Zn}$ 1 had $4.3 \mathrm{~nm}$ while $\mathrm{Zn}-2$ had $4.4 \mathrm{~nm}$ inter-layer distance, respectively. The peaks belonging to $\mathrm{Zn}-2$ were spread over a wide range and were rather weak in comparison to the sharp

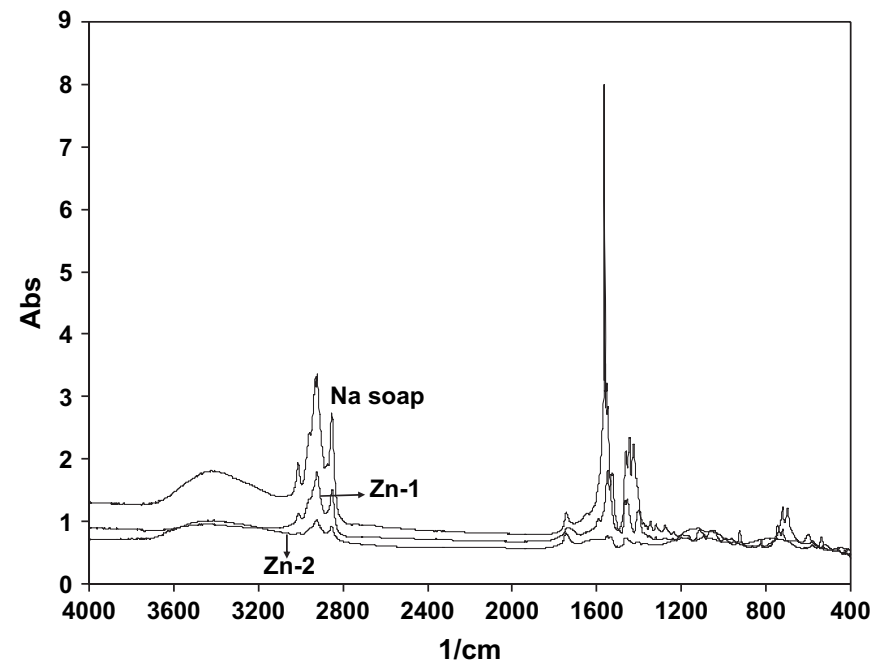

Fig. 3. IR spectra of $\mathrm{Na}$ and $\mathrm{Zn}$ soaps of RSO produced by (a) precipitation, Zn-1 and (b) metathesis, Zn-2. 

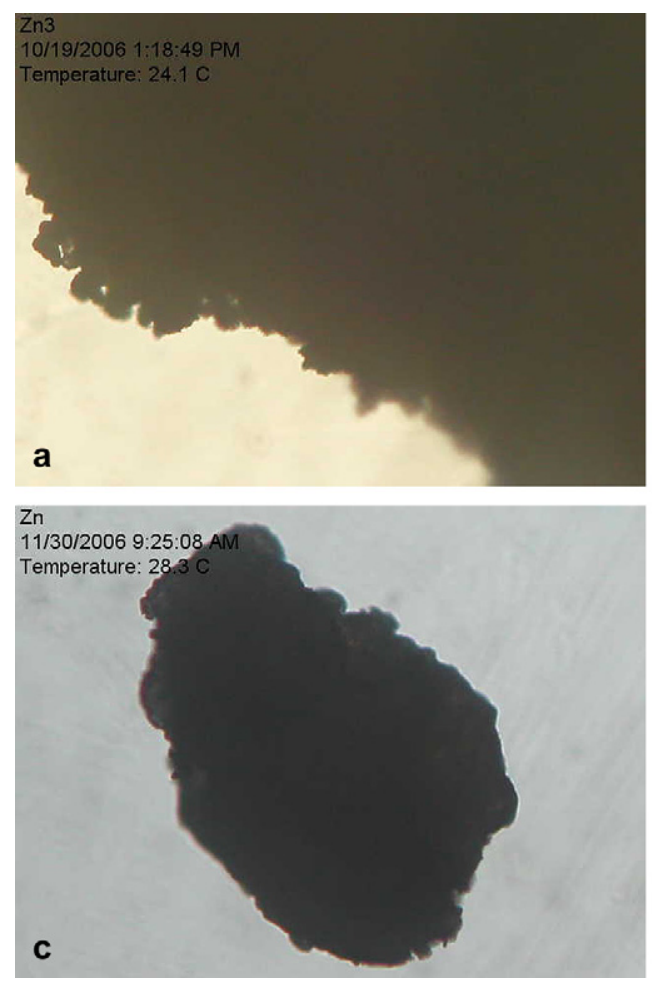

Fig. 4. Optical micrographs of $\mathrm{Zn}$ soaps of RSO.

(a) $\mathrm{Zn}-1$ at 24.1

and intense peaks expected for metal carboxylates. Studies have shown that the degree of crystallinity for a well-defined crystalline structure of heavy metal carboxylates can be seen best in terms of the sharpness of the pattern [22].

\subsubsection{IR spectroscopic measurements}

The IR spectra for Zn-2 shown in Fig. 3 show absorption bands due to $\mathrm{OH}$ stretching modes occurring in the range $3500-3200 \mathrm{~cm}^{-1}$ and observed as a broad band centered at approximately $3400 \mathrm{~cm}^{-1}$. This supports the possible formation of the metal hydroxide as confirmed by the high $\mathrm{O}$ and $\mathrm{Zn}$ content obtained from EDX analysis. For $\mathrm{Zn}-1$, the relative intensity of this band decreased significantly. For Zn-1, two intense peaks at 1400 and $1548 \mathrm{~cm}^{-1}$ assigned to the symmetric and antisymmetric $\left(\nu_{\mathrm{s}} \mathrm{COO}^{-}\right.$and $\left.\cup_{\mathrm{a}} \mathrm{COO}^{-}\right)$stretching modes were observed and correspond with the values reported in literature for zinc stearates $[21,23]$. However, for Zn-2, they appeared as weak bands at 1396 and $1554 \mathrm{~cm}^{-1}$. The other bands present at about 2920, 2850 and $1472 \mathrm{~cm}^{-1}$ correspond to the antisymmetric, symmetric and methylene scissoring modes $\left(\cup_{\mathrm{a}} \mathrm{CH}_{2}, \cup_{\mathrm{s}} \mathrm{CH}_{2}\right.$ and $\left.\delta_{\mathrm{s}} \mathrm{CH}_{2}\right)$ due to the alkyl chain present in the RSO structure. The IR spectra also indicate the existence of unreacted oil in $\mathrm{Zn}-1$ and $\mathrm{Zn}-2$ appearing as weak absorption bands between 1745 and $1750 \mathrm{~cm}^{-1}$ corresponding to the $\mathrm{C}=\mathrm{O}$ stretching vibration of free esters of the oil.

\subsubsection{Phase transitions and thermal behaviour}

The $\mathrm{Zn}$ soaps of RSO are solids at room temperature. However, on heating, one or more phase transitions may be observed over the temperature range up to the onset of thermal decomposition. DSC measurements and optical microscope
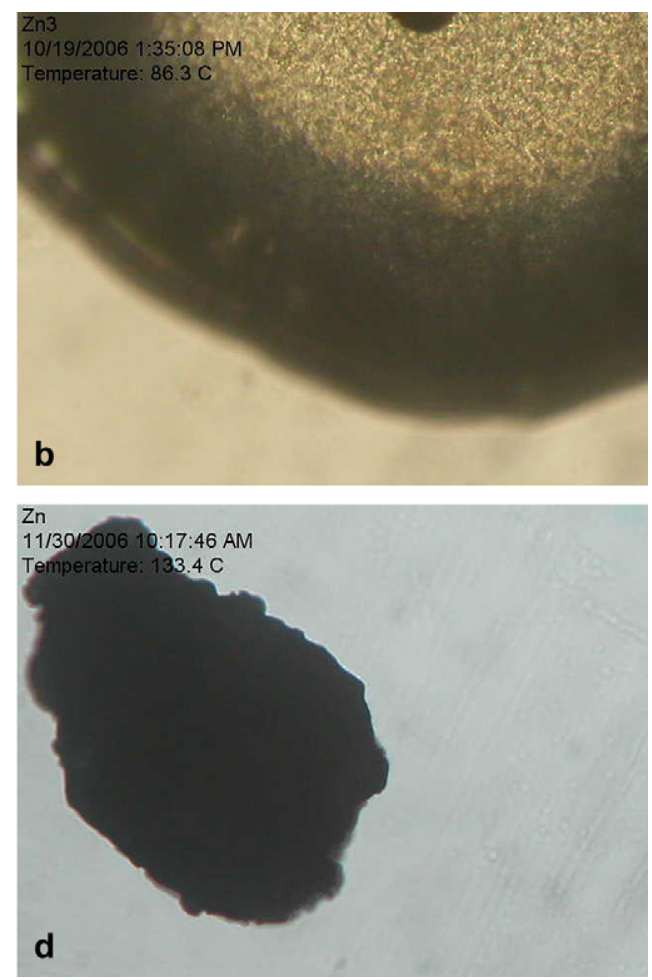

C, (b) Zn-1 at $86.3{ }^{\circ} \mathrm{C}$, (c) Zn-2 at $28.3{ }^{\circ} \mathrm{C}$ and (d) Zn-2 at $133.4{ }^{\circ} \mathrm{C}$.

examination were used to determine the transitions occurring during the thermal treatment of the Zn soaps of RSO. Optical micrographs showing the melting as observed with the digital camera are shown in Fig. 4.

A remarkable feature of the melting behaviour of the $\mathrm{Zn}$ soaps is that for $\mathrm{Zn}-1$, a clear transition to the liquid phase was observed at $86.3{ }^{\circ} \mathrm{C}$ while for $\mathrm{Zn}-2$, the melting was unclear but a decomposed material was obtained at the end of the thermal treatment. To gain more insight of this behaviour, the soaps were investigated with DSC up to $200{ }^{\circ} \mathrm{C}$ at a heating rate of $10{ }^{\circ} \mathrm{C} \mathrm{min}^{-1}$. The DSC curves in Fig. 5 show the single endothermic peak of a solid-liquid phase transition corresponding to melting for $\mathrm{Zn}-1$ observed at about $82{ }^{\circ} \mathrm{C}$

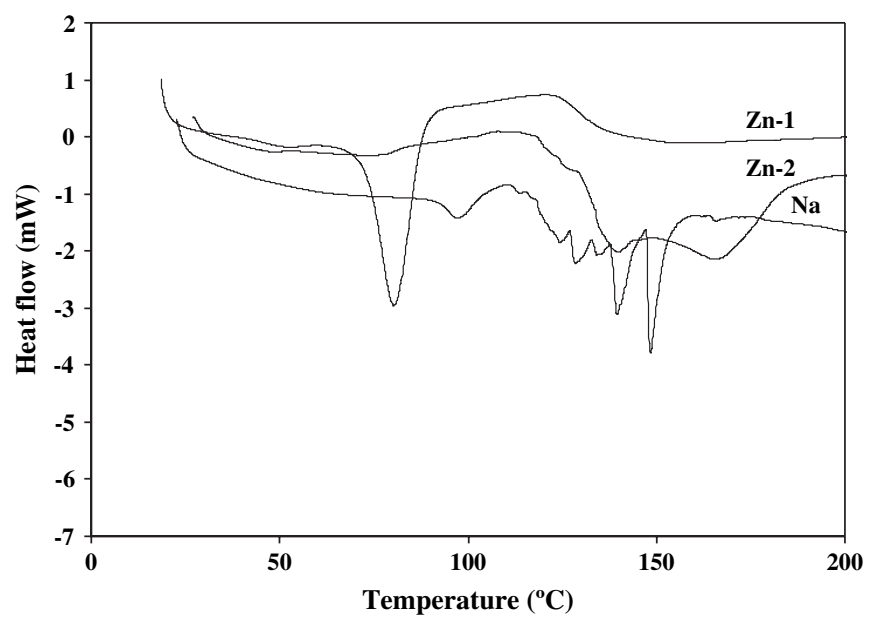

Fig. 5. DSC curves of Na and Zn soaps of RSO produced by (a) precipitation, Zn-1 and (b) metathesis, Zn-2. 


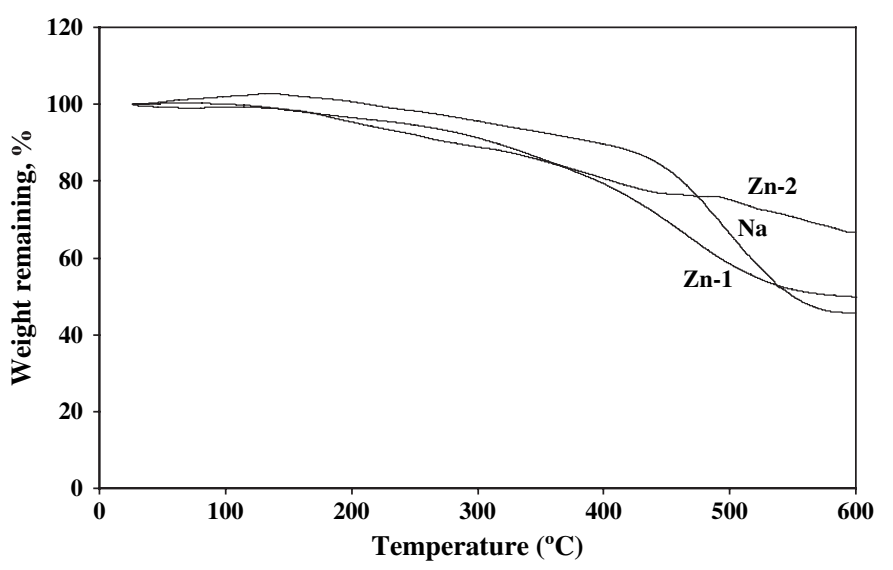

Fig. 6. TGA curves of $\mathrm{Na}$ and $\mathrm{Zn}$ soaps of RSO produced by (a) precipitation, $\mathrm{Zn}-1$ and (b) metathesis, $\mathrm{Zn}-2$.

confirming the optical microscopy transition at about the same temperature range. This value is however lower than the values reported for $\mathrm{Zn}$ stearate $[21,23]$ and could be attributed to the presence of unsaturation in RSO. It has been reported that only a single peak corresponding to a solid-liquid transition is observed for unsaturated zinc(II) octadecenoates and octadecadienoates using differential thermal analysis (DTA) measurements [24]. For $\mathrm{Zn}-2$, the peak observed between 130 and $160{ }^{\circ} \mathrm{C}$ is attributed to the decomposition of the soap as it also recorded about $3 \%$ weight loss in the TGA data. The soaps are thermally stable up to $200{ }^{\circ} \mathrm{C}$ as they showed less than $5 \%$ weight loss at this temperature. From the curves shown in Fig. 6, the decomposition is a one-step process occurring between 250 and $400{ }^{\circ} \mathrm{C}$. The weight percent remaining at $600{ }^{\circ} \mathrm{C}$ for the $\mathrm{Zn}$ soap samples were about 50 and $67 \%$ for $\mathrm{Zn}-1$ and $\mathrm{Zn}-2$, respectively. It would appear that $\mathrm{Zn}-2$ is more stable since it had a higher residue arising from the hydroxide present which yields the metal oxide as part of the decomposition products. The products of pyrolysis of zinc(II) soaps have been reported to contain ketones and carbon dioxide as gaseous products, with a mixture of zinc carbonate and oxide as solid residues in some cases [24].

\subsection{Characterization of ERSO}

RSO is an unsaturated triglyceride that contains about $11 \%$ stearic, $21 \%$ oleic, $37 \%$ linoleic and $23 \%$ linolenic acid. Three of these are unsaturated acids: oleic (18:1), linoleic (18:2) and linolenic (18:3). Previous studies [16] using ${ }^{13} \mathrm{C}$ NMR have shown the chemical structure of RSO to be as represented in Fig. 7. The double bonds may also be converted into the more reactive oxirane moiety by reaction with peracids or peroxides (Fig. 8).

The epoxide rings from ERSO have been shown to react with hydrogen chloride generated by the dehydrochlorination of PVC thus preventing further dehydrochlorination [3,14].

The IR spectra of RSO and ERSO are shown in Fig. 9. From the spectra, it can be seen that all the bands present in RSO are also present in ERSO as their chemical structures are close. However, the most notable difference is the appearance of a small absorption band at about $820 \mathrm{~cm}^{-1}$ in ERSO attributed to the mono-substituted oxirane ring [25] and a small broad absorption band at about $3430 \mathrm{~cm}^{-1}$ in ERSO completely absent in RSO due to the side reaction occurring during epoxidation resulting in glycol formation [16] and the partial disappearance of the band at $1640 \mathrm{~cm}^{-1}$ in RSO from ERSO due to $\mathrm{C}=\mathrm{C}$ double bonds.

The thermal degradation of ERSO and the phase transitions during the dynamic thermal treatment were investigated using TGA and DSC analysis and shown in Figs. 10 and 11, respectively. The thermal behaviour of ERSO from the TG curves shows that ERSO is thermally stable at temperatures up to $200{ }^{\circ} \mathrm{C}$ as it showed less than $1 \%$ weight loss. However, above $400{ }^{\circ} \mathrm{C}$, a $30 \%$ weight loss was recorded relating to the decomposition of the oil. At the end of the thermal treatment at $600{ }^{\circ} \mathrm{C}$, the total weight remaining was $38.7 \%$. From the DSC analysis, a phase transition occurred between 150 and $170{ }^{\circ} \mathrm{C}$ and appears to be the glass transition temperature $\left(T_{\mathrm{g}}\right)$. It could be attributed to the fact that at high temperatures, ERSO forms cross-links within the molecule and gels leading to the formation of a solid phase.

\subsection{PVC thermal stability}

The colouration of PVC formulations is a consequence of polymer dehydrochlorination, which is apparent at very early stages of the reaction after the elimination of about $0.1 \%$ of the hydrogen chloride unit [1]. As seen in Fig. 12 while gelled films at $140{ }^{\circ} \mathrm{C}$ had YI between 4 and 10 , the films heated under drastic conditions of $160{ }^{\circ} \mathrm{C}$ for $30 \mathrm{~min}$ had YI values between 28 and 42. The change in YI for the PVC plastigels were minimal in the films stabilized with ERSO. Epoxy groups of ERSO react with $\mathrm{HCl}$ evolved by

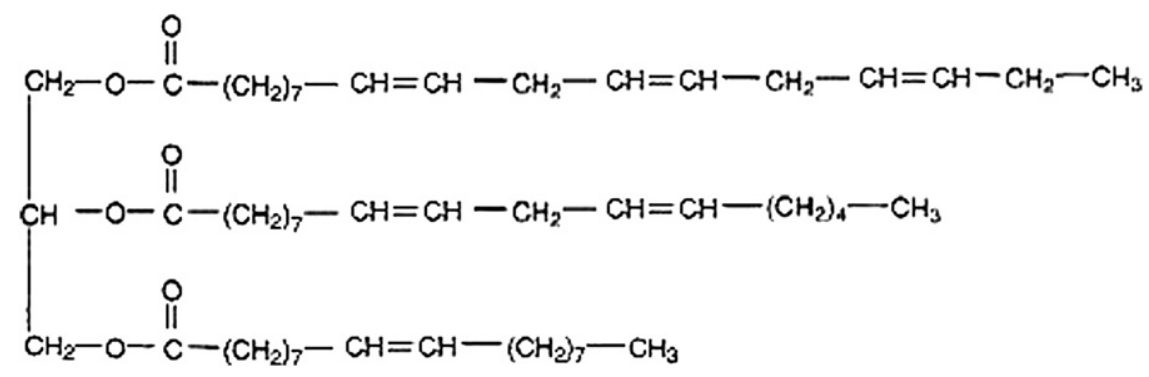

Fig. 7. Chemical structure of RSO. 


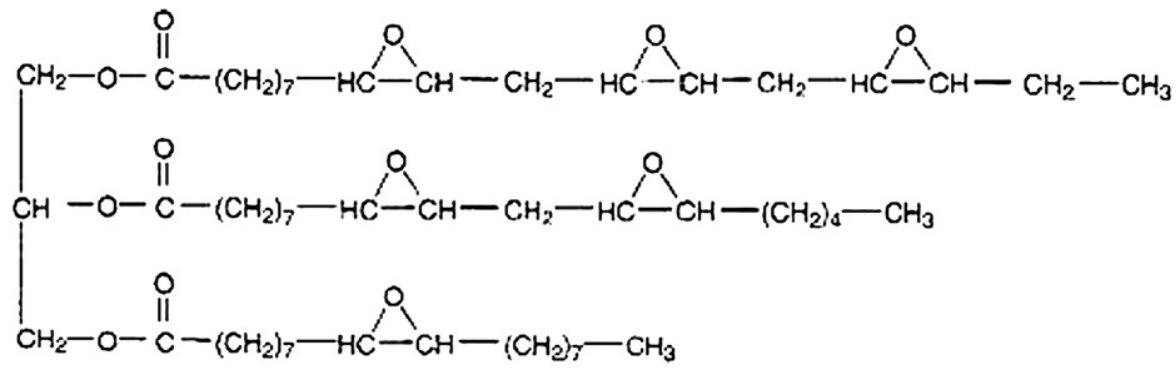

Fig. 8. Chemical structure of ERSO.

dehydrochlorination of PVC. Thus autoacceleration of dehydrochlorination by evolved $\mathrm{HCl}$ is prevented since it is captured by epoxy groups.

$\mathrm{HCl}+$

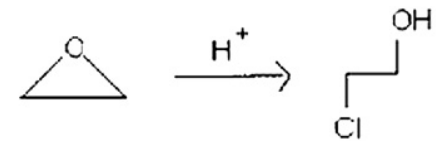

For films heated at $160{ }^{\circ} \mathrm{C}$ lower YI value was observed for ERSO added film than that YI of film without any additive.

Zinc soap's carboxylate group substitutes allylic chlorines in PVC forming esters as shown in Eq. (6) and makes PVC more resistant to heat.

$$
\left(\mathrm{RCOO}^{-}\right)_{2} \mathrm{Zn}_{(\mathrm{s})}+2 \mathrm{R}_{1}-\mathrm{Cl} \rightarrow 2 \mathrm{RCOOR}_{1}+\mathrm{ZnCl}_{2(\mathrm{~s})}
$$

where $\mathrm{R}_{1}$ represents the PVC polymer chain except an allylic chlorine. These esters also are unstable and PVC decomposes in long heating periods.

For long period of heating at $160{ }^{\circ} \mathrm{C}, \mathrm{ZnCl}_{2}$ accelerating effect was observed for $\mathrm{Zn}-1$ and $\mathrm{Zn}$-2-containing films. This was observed by previous investigators using zinc soaps as thermal stabilizers [6]. When the $\mathrm{ZnCl}_{2}$ concentration exceeds a certain level, it accelerates dehydrochlorination. Films containing Zn-1 had higher YI values compared to the films with $\mathrm{Zn}-2$. The $\mathrm{Zn}(\mathrm{OH})_{2}$ in $\mathrm{Zn}-2$ captures the $\mathrm{HCl}$ evolved and acceleration of dehydrochlorination was prevented to some extent. This difference could be attributed to the dual

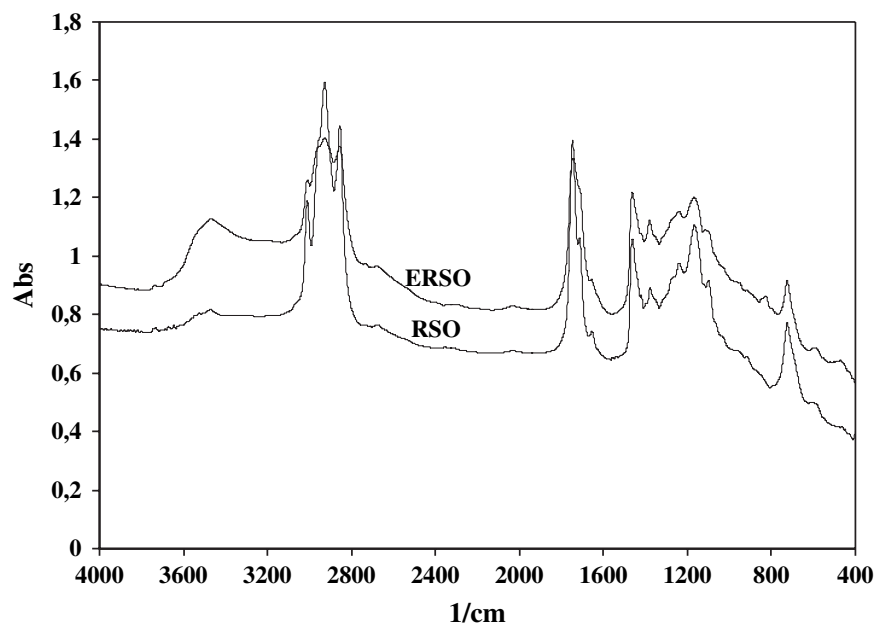

Fig. 9. FTIR spectra of RSO and ERSO. action of the metal carboxylate and hydroxide present in Zn-2. Zinc hydroxide will be converted to zinc oxide during heating and zinc oxide will neutralise $\mathrm{HCl}$ evolved during dehydrochlorination according to the reaction

$\mathrm{ZnO}+2 \mathrm{HCl} \rightarrow \mathrm{ZnCl}_{2}+\mathrm{H}_{2} \mathrm{O}$

Zinc chloride formed in reactions (6) and (7) is a Lewis acid and it will also accelerate dehydrochlorination after its concentration reaches a certain level. Using Zn-1 or Zn-2 and ERSO together gave lowered YI value than using Zn-1 or $\mathrm{Zn}-2$ alone. This shows the combined effect of the metal soaps and ERSO as effective stabilizers for PVC plastisols.

\subsection{Kinetics of dehydrochlorination}

It is well known that the efficiency of a heat stabilizer is measured by its ability to prevent degradation. The stabilizing function follows two primary mechanisms: reacting with the liberated $\mathrm{HCl}$ and reacting with the polymer to prevent further $\mathrm{HCl}$ loss, and the $\mathrm{HCl}$ liberated in the early stages of degradation must be neutralized to prevent an inherent autocatalytic effect [26]. For the kinetic study of dehydrochlorination of PVC plastigels, conductivity measurements were used. The kinetic curves obtained at 140 and $160{ }^{\circ} \mathrm{C}$ are shown in Figs. 13 and 14, respectively. The curves have a similar pattern: an

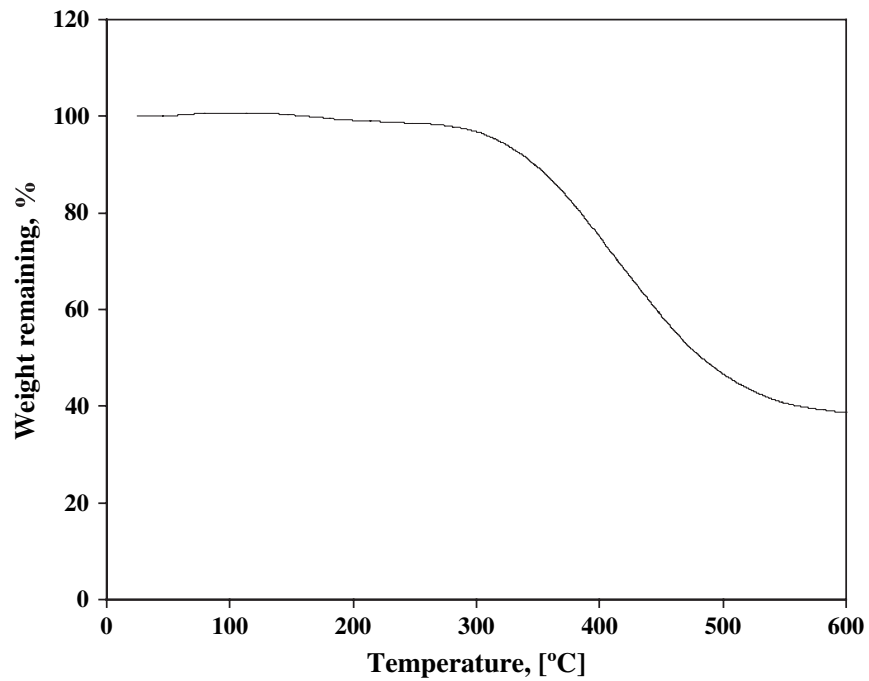

Fig. 10. TG curve of ERSO 


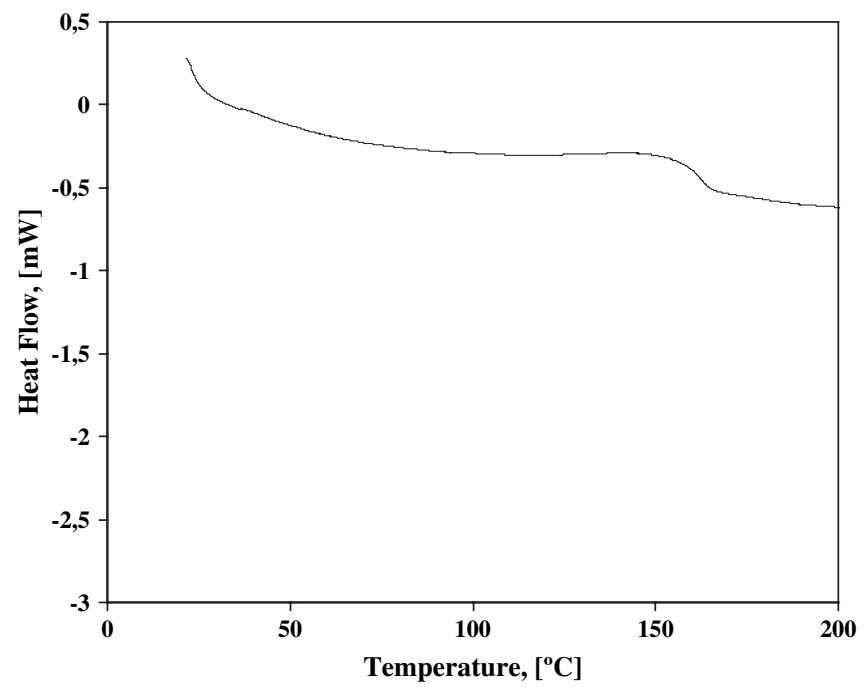

Fig. 11. DSC curve of ERSO.

initial slow rate of $\mathrm{HCl}$ evolution at the beginning of the heat treatment followed by a more rapid dehydrochlorination after consumption of the stabilizers. In the absence of metal soaps, ERSO retarded the rate of $\mathrm{HCl}$ evolution by increasing the induction time from 4.00 to $8.20 \mathrm{~h}$ at $140{ }^{\circ} \mathrm{C}$ as shown in Table 2 . The stabilizing effect of ERSO on the thermal dehydrochlorination of PVC has been reported to result from the facile reaction of $\mathrm{HCl}$ with the epoxy group to form chlorohydrin, which is thought to reduce the autocatalytic effect of the $\mathrm{HCl}$ evolved in the initial stages of dehydrochlorination [14]. The oxirane ring reacts with $\mathrm{HCl}$ thus inhibiting the degradation. For the single soap, the induction time also increased as expected because the presence of the carboxylate group substituted the allylic chlorines through an O-alkylation reaction. However, this substitution reaction is not permanent due to a re-exchange caused by free $\mathrm{HCl}$ in which the ester is able to react to regenerate allylic chlorine atoms and carboxylic acid [27]. The addition of

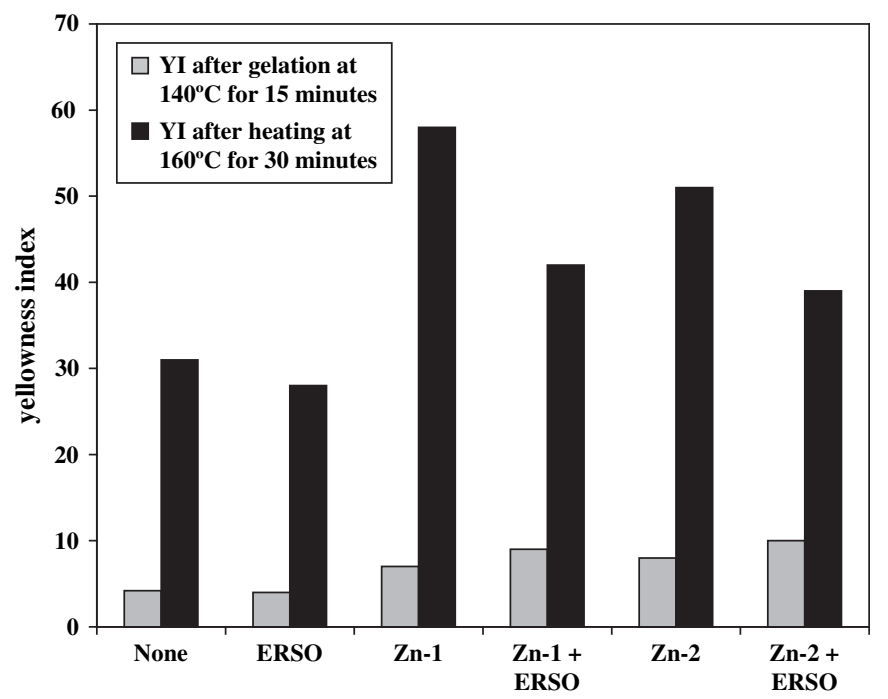

Fig. 12. Yellowness index of the films after gelation at $140{ }^{\circ} \mathrm{C}$ and further heating at $160^{\circ} \mathrm{C}$ for $30 \mathrm{~min}$.

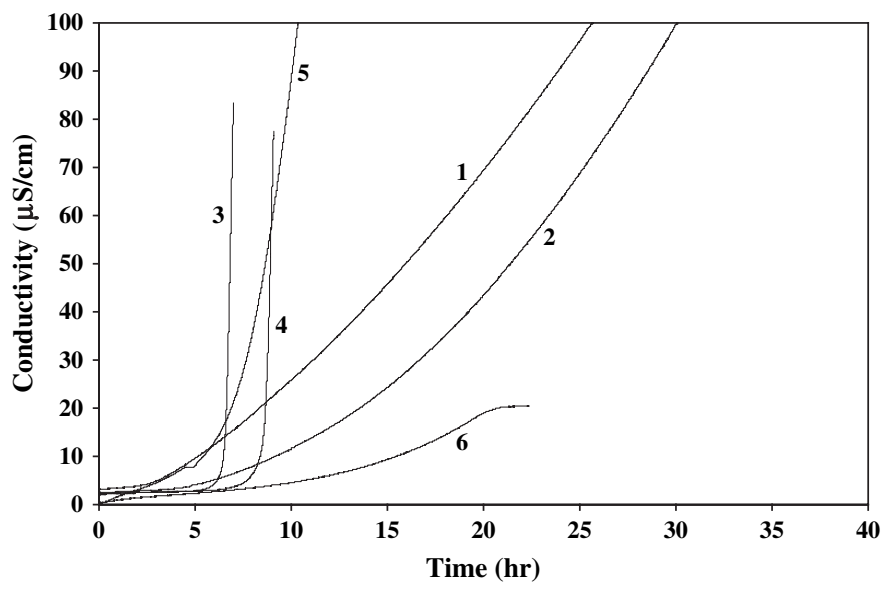

Fig. 13. The change of conductivity of aqueous solution with respect to time at $140{ }^{\circ} \mathrm{C}$ for PVC plastigels stabilized with ERSO and/or Zn metal soap of RSO. (1) Unstabilized, (2) ERSO, (3) Zn-1, (4) Zn-1 + ERSO, (5) Zn-2 and (6) Zn$2+$ ERSO.

ERSO suppressed this effect as the evolution of $\mathrm{HCl}$ was reduced as indicated by the increase in induction times. The synergism observed in the thermal stabilization of PVC using ERSO and $\mathrm{Zn}$ soaps of RSO could be explained by the esterification and etherification of the allylic chlorine atom as the combined effect of these two reactions would reduce the amount of $\mathrm{HCl}$ evolved [5].

The rate of dehydrochlorination is dependent on a number of factors including temperature. At $160{ }^{\circ} \mathrm{C}$, the rate of dehydrochlorination was higher, as the induction period decreased for all samples and decomposition occurred in less than $4 \mathrm{~h}$. However, the induction time was highest for the sample stabilized with $3 \mathrm{wt} \%$ ERSO $(3.50 \mathrm{~h})$. When stability times are compared it is seen that the stability time of samples having zinc soap and ERSO was longer than the ones with only zinc soap since reactions (5) and (6) occur simultaneously. $\mathrm{Zn}-2$ soap seemed to have a better stabilizing action than $\mathrm{Zn}-1$ since it contained $\mathrm{ZnO}$ and reacted with $\mathrm{HCl}$ according to Eq. (7).

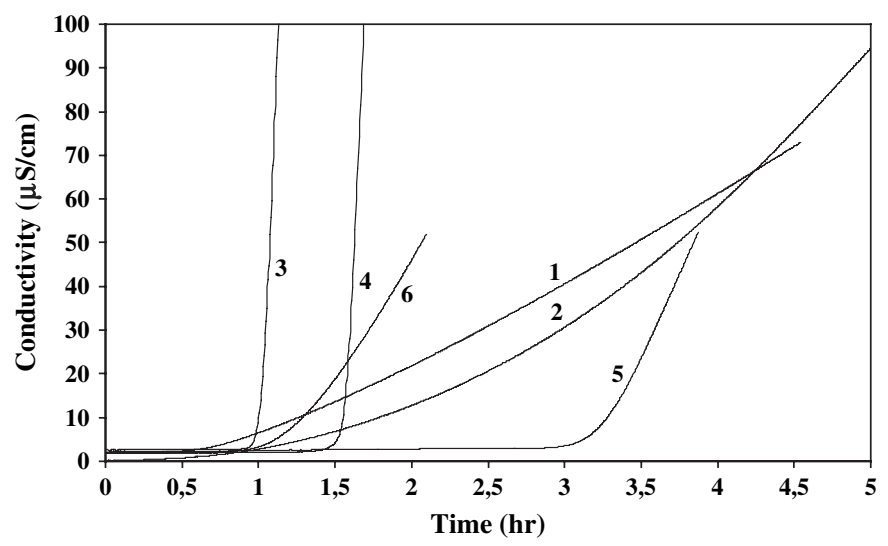

Fig. 14. The change of conductivity of aqueous solution with respect to time at $160{ }^{\circ} \mathrm{C}$ for PVC plastigels stabilized with ERSO and/or Zn metal soap of RSO. (1) Unstabilized, (2) ERSO, (3) Zn-1, (4) Zn-1 +ERSO, (5) Zn-2 and (6) Zn-2 + ERSO. 
When $\mathrm{Zn}-1$ and $\mathrm{Zn}-2$ were used together with ERSO both induction time and stability time were longer than those when they were used alone at $140{ }^{\circ} \mathrm{C}$ (Table 2). On the other hand at $160^{\circ} \mathrm{C} \mathrm{Zn-2}$ and ERSO had lower induction and stability times than was the case if $\mathrm{Zn}-2$ was used alone. This could be the result of acceleration of dehydrochlorination due to accumulation of $\mathrm{ZnCl}_{2}$ by reactions (6) and (7) by heating longer periods than one hour and fast consumption of epoxy groups of ERSO by hydrogen chloride according to reaction (5). For short heating periods yellowness index values indicated that both $\mathrm{Zn}-1$ and $\mathrm{Zn}-2$ were more efficient in thermal stabilization of PVC when they were used simultaneously with ERSO.

The rates of dehydrochlorination were computed from the slopes of the kinetic curves obtained in the first step of dehydrochlorination $\left(k_{\mathrm{i}}\right)$ where $\mathrm{HCl}$ gas started to evolve and the second step $\left(k_{\mathrm{lr}}\right)$ where the acceleration effect of $\mathrm{HCl}$ and the products formed at the end of the degradation could be observed. The rate constants obtained at 140 and $160^{\circ} \mathrm{C}$ are given in Tables 2 and 3, respectively. From the values obtained, the reaction rate constant of the dehydrochlorination of PVC changed with the additives. The addition of the $\mathrm{Zn}$ soaps increased the rate of the reaction but with the addition of ERSO, the catalytic effect was eliminated. The rate constants were found to be $5.0 \times 10^{-6}$ and $3.4 \times 10^{-6} \mathrm{~min}^{-1}$ for $\mathrm{Zn}-1$ and $\mathrm{Zn}-1+$ ERSO, respectively. A similar trend was observed for $\mathrm{Zn}-2$ and $\mathrm{Zn}-2+$ ERSO having values $13.3 \times 10^{-6}$ and $2.2 \times 10^{-6} \mathrm{~min}^{-1}$ at $140^{\circ} \mathrm{C}$. The linear region rate constants obtained for the kinetic curves were generally higher than the values obtained in the initial region as expected due to the high rate of dehydrochlorination after the consumption of the stabilizers and the autocatalytic effect of the $\mathrm{HCl}$ evolved. The samples stabilized with only ERSO had the lowest rate constants in the linear region at both temperatures, showing its stabilizing effect on PVC. This effect can be considered to result from the formation of cross-links in the polymer arising from the gel formation of ERSO at high temperatures.

\subsubsection{Activation energy and pre-exponential factor}

In the thermal degradation of $\mathrm{PVC}, \mathrm{HCl}$ gas is evolved and the product is a solid residue. Hence, the reaction rate equation used to study a heterogeneous reaction involving gaseous and a solid residue is used to determine the kinetic parameters such as activation energy $\left(E_{\mathrm{a}}\right)$ and pre-exponential factor $(A)$.

Table 2

Dehydrochlorination data at $140{ }^{\circ} \mathrm{C}$ for PVC films containing $\mathrm{Zn}$ soaps of RSO and/or ERSO

\begin{tabular}{|c|c|c|c|c|}
\hline \multirow[t]{2}{*}{ Additive } & \multirow{2}{*}{$\begin{array}{l}\text { Induction } \\
\text { time } \\
\text { (h) }\end{array}$} & \multirow{2}{*}{$\begin{array}{l}\text { Stability } \\
\text { time } \\
\text { (h) }\end{array}$} & \multicolumn{2}{|c|}{ Rate of dehydrochlorination } \\
\hline & & & $\begin{array}{l}\text { Initial region } \\
k_{\mathrm{i}} \times 10^{6}\left(\mathrm{~min}^{-1}\right)\end{array}$ & $\begin{array}{l}\text { Linear region } \\
k_{\mathrm{lr}} \times 10^{6}\left(\mathrm{~min}^{-1}\right)\end{array}$ \\
\hline None & 4.0 & 16.6 & 1.0 & 4.1 \\
\hline ERSO & 8.2 & 21.9 & 1.1 & 4.1 \\
\hline $\mathrm{Zn}-1$ & 6.6 & 6.8 & 5.0 & 16.3 \\
\hline $\mathrm{Zn}-1+\mathrm{ERSO}$ & 8.7 & 8.9 & 3.4 & 44.6 \\
\hline $\mathrm{Zn}-2$ & 7.0 & 8.6 & 13.3 & 28.5 \\
\hline Zn-2 + ERSO & 8.5 & 24.2 & 2.2 & 9.6 \\
\hline
\end{tabular}

Table 3

Dehydrochlorination data at $160{ }^{\circ} \mathrm{C}$ for PVC films containing $\mathrm{Zn}$ soaps of RSO and/or ERSO

\begin{tabular}{|c|c|c|c|c|}
\hline \multirow[t]{2}{*}{ Additive } & \multirow{2}{*}{$\begin{array}{l}\text { Induction } \\
\text { time } \\
\text { (h) }\end{array}$} & \multirow{2}{*}{$\begin{array}{l}\text { Stability } \\
\text { time } \\
\text { (h) }\end{array}$} & \multicolumn{2}{|c|}{ Rate of dehydrochlorination } \\
\hline & & & $\begin{array}{l}\text { Initial region } \\
k_{\mathrm{i}} \times 10^{6}\left(\mathrm{~min}^{-1}\right)\end{array}$ & $\begin{array}{l}\text { Linear region } \\
k_{1 \mathrm{r}} \times 10^{6}\left(\mathrm{~min}^{-1}\right)\end{array}$ \\
\hline None & 0.65 & 3.56 & 2.6 & 10.9 \\
\hline ERSO & 3.50 & 3.75 & 7.4 & 20.6 \\
\hline Zn-1 & 1.02 & 1.08 & 48.8 & 377.0 \\
\hline Zn-1 + ERSO & 1.57 & 1.63 & 40.1 & 187.0 \\
\hline $\mathrm{Zn}-2$ & 3.22 & 3.87 & 5.3 & 21.1 \\
\hline $\mathrm{Zn}-2+\mathrm{ERSO}$ & 1.14 & 1.28 & 45.4 & 198.6 \\
\hline
\end{tabular}

The activation energy for the degradation was evaluated experimentally by carrying out the reaction at two different temperatures $\left(140\right.$ and $\left.160{ }^{\circ} \mathrm{C}\right)$ and applying the Arrhenius equation. The dependence of rate constant on temperature is represented by

$k=A \mathrm{e}^{-E_{\mathrm{a}} / R T}$

where $k$ is rate constant, $A$ is pre-exponential factor, $E_{\mathrm{a}}$ is activation energy $\left(\mathrm{kJ} \mathrm{mol}^{-1}\right), R$ is gas constant $\left(8.314 \mathrm{~J} \mathrm{~mol}^{-1}\right.$ $\mathrm{K}^{-1}$ ) and $T$ is temperature $(\mathrm{K})$.

It might be expected that the addition of a heat stabilizer to PVC should result in higher values of activation energy for the dehydrochlorination and that the more effective the heat stabilizer the higher the activation energy values. From the values given in Table 4, the synergistic effect of $\mathrm{Zn}$ soap and ERSO was clearly evident as they presented the highest activation energies. $\mathrm{Zn}$ carboxylates have been shown to be effective stabilizers for PVC at the start of the dehydrochlorination reaction as they are more reactive towards the allylic chlorine [27]. The pre-exponential factor $(A)$ of the initial rate of dehydrochlorination was also evaluated and the values obtained are given in Table 4 . The pre-exponential factors vary with the activation energies which could be as a result of reactions with different mechanisms. To eliminate this effect on activation energy, the variation of In $A$ as a function of $E_{\mathrm{a}}$ was plotted as shown in Fig. 15. The graphs show a linear relation in both regions describing the reaction ability of the system and can be expressed as

In $A=0.29 E_{\mathrm{a}}-12.26$ (initial region)

In $A=0.28 E_{\mathrm{a}}-10.24$ (linear region)

Table 4

Activation energies and pre-exponential factors for the dehydrochlorination reaction

\begin{tabular}{lcclll}
\hline Additive & \multicolumn{2}{c}{ Activation energy $\left(\mathrm{kJ} \mathrm{mol}^{-1}\right)$} & & \multicolumn{2}{c}{ Pre-exponential factor $\left(\mathrm{s}^{-1}\right)$} \\
\cline { 2 - 3 } \cline { 5 - 6 } & Initial region & Linear region & & Initial region & Linear region \\
\hline None & 68 & 72 & & $4.4 \times 10^{2}$ & $5.8 \times 10^{3}$ \\
ERSO & 109 & 89 & & $1.3 \times 10^{8}$ & $1.3 \times 10^{6}$ \\
Zn-1 & 167 & 233 & $1.1 \times 10^{16}$ & $4.9 \times 10^{23}$ \\
$Z n-1+$ ERSO & 183 & 106 & & $4.9 \times 10^{17}$ & $1.3 \times 10^{9}$ \\
$Z n-2$ & 69 & 125 & & $6.7 \times 10^{3}$ & $1.1 \times 10^{11}$ \\
$Z n-2+$ ERSO & 224 & 138 & $4.3 \times 10^{22}$ & $2.6 \times 10^{23}$ \\
\hline
\end{tabular}




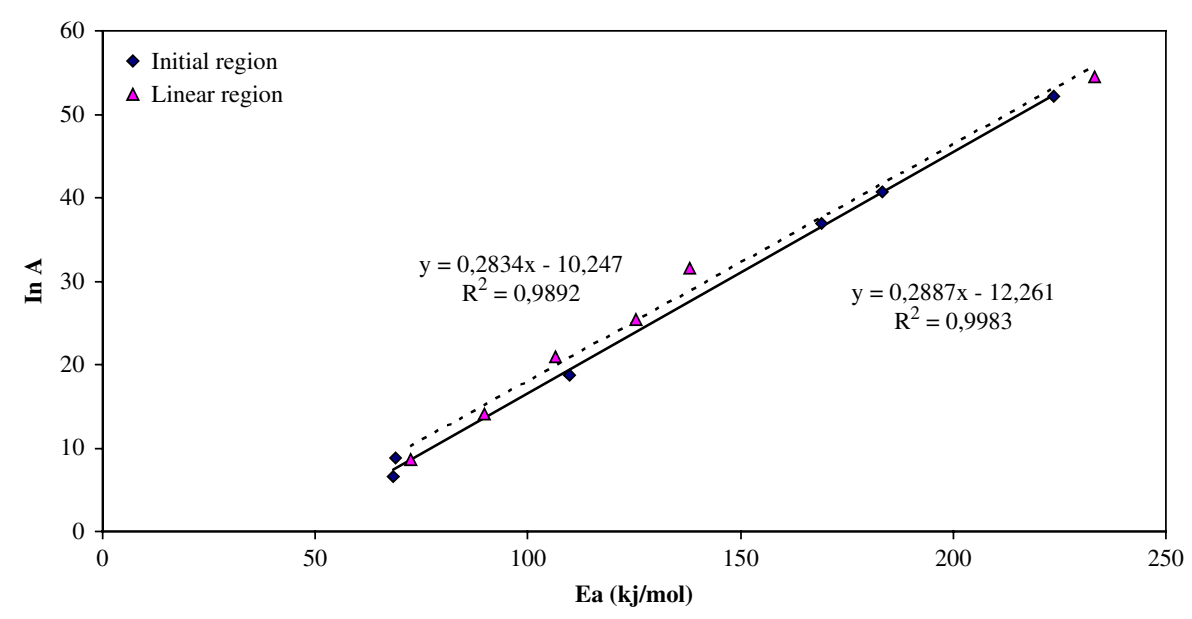

Fig. 15. In $A$ vs $E_{\mathrm{a}}$ for the dehydrochlorination process of PVC plastigels stabilized with Zn soaps of RSO and/or ERSO.

This behaviour is shown by a large group of heterogeneous reactions and is known as the kinetic compensation effect [27]; the equation obtained here is consistent with values in the literature for the dehydrochlorination of PVC using organo-tin, metal oxide and natural zeolite stabilizers $[4,6,8]$.

\section{Conclusions}

Zinc soaps of rubber seed oil (RSO) prepared by metathesis in alcohol solution and by precipitation techniques were characterized. Infrared spectroscopy (IR), X-ray diffraction (XRD), thermal gravimetric analysis (TGA) and differential scanning calorimetry (DSC) were used to investigate the structure and thermal properties of the soaps and ERSO. The thermal behaviour of these soaps and/or epoxidised rubber seed oil (ERSO) on the thermal stability of PVC plastigels have been examined at 140 and $160^{\circ} \mathrm{C}$. A synergistic effect of the metal soaps and ERSO as effective stabilizers for PVC plastisols was observed from induction and stability times of the films for short heating periods. Dehydrochlorination is found to occur through a two-step route in which the first step corresponds to an initial low rate of $\mathrm{HCl}$ evolution and the second is attributed to the autoacceleration effect of $\mathrm{HCl}$ evolution after the consumption of the stabilizers. Kinetic parameters: rate constant, activation energy and pre-exponential factor for the initial rate of the dehydrochlorination have also been reported. The initial dehydrochlorination of the PVC plastigels is strongly inhibited in the presence of $\mathrm{Zn}$ soaps of RSO. ERSO, used alone, slowed the rate of dehydrochlorination and does give a synergistic effect in combination with $\mathrm{Zn}$ soaps of RSO. For long heating periods and higher temperatures $\mathrm{Zn}$ soaps are detrimental to thermal stabilization of PVC due to accumulation of the Lewis acid $\mathrm{ZnCl}_{2}$.

\section{Acknowledgements}

The authors are grateful to the authorities of the College of Education, Warri, Nigeria, for the study/training leave of one of the authors (T.O.E.) and Turkish State Planning Organization Project 2002, K120 390.

\section{References}

[1] Baltacioğlu H, Balköse D. Effect of zinc stearate and/or epoxidised soybean oil on gelation and thermal stability of PVC-DOP plastigels. J Appl Polym Sci 1999;74:2488-98.

[2] Hollande S, Laurent J. Study of discolouring change in PVC, plasticizer and plasticized PVC films. Polym Degrad Stab 1997;55:141-5.

[3] Okieimen FE, Ebhoaye JE. Thermal dehydrochlorination of PVC in the presence of rubber seed oil. Angew Makromol Chem 1993;206:11-20.

[4] Arkiş E, Balkose D. Thermal stabilisation of poly(vinyl chloride) by organotin compounds. Polym Degrad Stab 2005;88:46-51.

[5] Benaniba MT, Belhareche-Bensemra N, Gelbard G. Stabilizing effect of epoxidised sunflower oil on the thermal degradation of poly(vinyl chloride). Polym Degrad Stab 2001;74:501-5.

[6] Atakul S, Balköse D, Ulku S. Synergistic effect of metal soaps and natural zeolite on poly(vinyl chloride) thermal stability. J Vinyl Addit Technol 2005;11:47-56.

[7] Gökçel HI, Balköse D. Thermal degradation of poly(vinyl chloride) plastigels. Adv Polym Tech 1998;17:63-71.

[8] Gupta MC, Viswanath SG. Role of metal oxides in the thermal degradation of poly(vinyl chloride). Ind Eng Chem Res 1998;37:2707-12.

[9] Benaniba MT, Belhareche-Bensemra N, Gelbard G. Stabilization of PVC by epoxidized sunflower oil in the presence of zinc and calcium stearates. Polym Degrad Stab 2003;82:245-9.

[10] Okieimen FE. Studies in the utilisation of epoxidized vegetable oils as thermal stabiliser for poly(vinyl chloride). Indus Crops Prod 2002;15:71-5.

[11] Gonzalez-Ortiz LJ, Arellano M, Jasso CF, Mendizabal E, SanchezPena JM. Thermal stability of plasticized poly(vinyl chloride) compounds stabilized with pre-heated mixtures of calcium and/or zinc stearates. Polym Degrad Stab 2005;90:154-61.

[12] Bacaloglu R, Stewen U. Study of PVC degradation using a fast computer scanning procedure. J Vinyl Addit Technol 2001;7:149-55.

[13] Fisch MH, Bacaloglu R. Kinetics and mechanism of the thermal degradation of poly(vinyl chloride). J Vinyl Addit Technol 1995;4:233-40.

[14] Okieimen FE, Ebhoaye JE. Studies in the thermal degradation of poly (vinyl chloride). J Appl Polym Sci 1993;48:1853-8.

[15] Joseph R, Alex R, Vinod VS, Premalatha CK, Kuriakose B. Studies on epoxidised rubber seed oil as plasticizer for acrylonitrile rubber. J Appl Polym Sci 2003;88:668-73.

[16] Okieimen FE, Pavithran C, Bakare IO. Epoxidation and hydroxylation of rubber seed oil: one-pot multi-step reactions. Eur J Lipid Sci Technol 2005;107:330-6.

[17] Bakare IO, Pavithran C, Okieimen FE, Pillai CKS. Polyesters from renewable resources: preparation and characterization. J Appl Polym Sci 2006;100:3748-55.

[18] Balköse D, Gökçel HI, Göktepe SE. Synergism of Ca/Zn soaps in poly (vinyl chloride) thermal stability. Eur Polym J 2001;37:1191-7. 
[19] Starnes Jr WH, Du B, Kim S, Zaikov VG, Ge X, Culyba EK. Thermal stabilization and plasticization of poly(vinyl chloride) by ester thiols: update and current status. Thermochim Acta 2006;442:78-80.

[20] Okieimen FE. Thermal stabilization of PVC: effect of rubber seed oil derivatives on the thermal degradation of PVC. J Sci Ind Res 2000;59: $563-8$.

[21] Gonen M, Balköse D, Inal F, Ulku S. Zinc stearate production by precipitation and fusion processes. Ind Eng Chem Res 2005;44:1627-33.

[22] Vold RD, Hattiangdi GS. Characterization of heavy metal soaps by X-ray diffraction. Ind Eng Chem 1949;41:2311-20.

[23] Barman S, Vasudevan S. Melting of saturated fatty acid zinc soaps. J Phys Chem B 2006;110:22407-14.
[24] Akanni SM, Okoh EK, Burrows HD, Ellis HA. The thermal behaviour of divalent and higher valent metal soaps: a review. Thermochim Acta 1992;208:1-41.

[25] Colthup NB, Daly HL, Wiberly SE. Introduction to infrared and Raman spectroscopy. California: Academic Press; 1990.

[26] Burley JW, Hutton RE. A possible mechanism to explain the synergistic effect exhibited by mixtures of alkyl-tin mercaptoesters as stabilizers for PVC. Polym Degrad Stab 1981;3:285-94.

[27] Santamaria E, Edge M, Allen NS, Harvey HB, Mellor M, Orchisson J. New insights into the degradation mechanism of poly(vinyl chloride), based on the action of novel co-stabilizers. I. J Appl Polym Sci 2004;93:2731-43. 